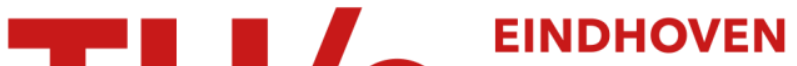 \\ UNIVERSITY OF \\ TECHNOLOGY
}

\section{Confined compression and torsion experiments on a pHEMA- gel in vatious bath concentrations}

Citation for published version (APA):

Roos, R. W., Petterson, R., \& Huyghe, J. M. R. J. (2013). Confined compression and torsion experiments on a pHEMA-gel in vatious bath concentrations. Biomechanics and Modeling in Mechanobiology, 12(3), 617-626.

https://doi.org/10.1007/s10237-012-0429-0

DOI:

10.1007/s10237-012-0429-0

Document status and date:

Published: 01/01/2013

Document Version:

Accepted manuscript including changes made at the peer-review stage

Please check the document version of this publication:

- A submitted manuscript is the version of the article upon submission and before peer-review. There can be important differences between the submitted version and the official published version of record. People interested in the research are advised to contact the author for the final version of the publication, or visit the $\mathrm{DOI}$ to the publisher's website.

- The final author version and the galley proof are versions of the publication after peer review.

- The final published version features the final layout of the paper including the volume, issue and page numbers.

Link to publication

\section{General rights}

Copyright and moral rights for the publications made accessible in the public portal are retained by the authors and/or other copyright owners and it is a condition of accessing publications that users recognise and abide by the legal requirements associated with these rights.

- Users may download and print one copy of any publication from the public portal for the purpose of private study or research.

- You may not further distribute the material or use it for any profit-making activity or commercial gain

- You may freely distribute the URL identifying the publication in the public portal.

If the publication is distributed under the terms of Article 25fa of the Dutch Copyright Act, indicated by the "Taverne" license above, please follow below link for the End User Agreement:

www.tue.nl/taverne

Take down policy

If you believe that this document breaches copyright please contact us at:

openaccess@tue.nl

providing details and we will investigate your claim. 


\section{Editorial Manager(tm) for Biomechanics and Modeling in Mechanobiology Manuscript Draft}

Manuscript Number:

Title: Confined compression and torsion experiments on a pHEMA-gel in various bath concentrations

Article Type: Original Research

Keywords: poly-HEMA; hydrogel; super-absorbent; shear modulus; osmotic pressure; concentration dependence

Corresponding Author: Jacques M. Huyghe, Dr. ir.

Corresponding Author's Institution:

First Author: Reinder Roos, M.D.

Order of Authors: Reinder Roos, M.D.;Jacques M. Huyghe, Dr. ir.;Rob Petterson, Ing.

Abstract: In the field of biological materials, the interplay between electrical, chemical and mechanical forces is complex.

With regard to cartilage, it is well recognised that both collagen fibres and proteoglycans contribute to its aggregate modulus. In addition, effects like decay, inhomogeneity and anisotropy complicate the interpretation of stiffness experiments. On the other hand, pHEMA hydrogel has demonstrated to serve the purpose of a model material embodying the interaction of electrical chemical and mechanical forces, while avoiding the complicating factor of the collagen network.

This study assesses the aggregate modulus of pHEMA hydrogel as a function of ionic strength. A combined 1D confined compression and torque experiment is performed on a thin cylindrical hydrogel sample, which is brought in equilibrium with respectively $1 \mathrm{M}, 0.1 \mathrm{M}$, and $0.03 \mathrm{M} \mathrm{NaCl}$. The sample was placed in a chamber that consists of a stainless steel ring placed on a sintered glass filter, and on top a sintered glass piston. Stepwise ionic loading was cascaded by stepwise 1D compression, measuring the total stress after equilibration of the sample elucidated the diagonal terms of the aggregate elasticity tensor. In addition, a torque experiment was interweaved by applying a harmonic angular displacement and measuring the torque, revealing the relation between aggregate shear modulus and salt concentration. The difference in osmotic pressure and shear stress between two ionic loading conditions can serve to fit screening parameters of osmotic pressure and shear stress models. Potential implications for mechanotransduction are discussed. 
Noname manuscript No.

(will be inserted by the editor)

\title{
Confined compression and torsion experiments on a pHEMA-gel in various bath concentrations
}

\author{
Reinder W. Roos · Rob Petterson • \\ Jacques M. Huyghe
}

Received: date / Accepted: date

\begin{abstract}
Keywords poly-HEMA · confined compression · shear modulus - osmotic pressure $\cdot$ concentration dependence

In the field of biological materials, the interplay between electrical, chemical and mechanical forces is complex. With regard to cartilage, it is well recognised that both collagen fibres and proteoglycans contribute to its aggregate modulus. In addition, effects like decay, inhomogeneity and anisotropy complicate the interpretation of stiffness experiments. On the other hand, pHEMA hydrogel has demonstrated to serve the purpose of a model material embodying the interaction of electrical chemical and mechanical forces, while avoiding the complicating factor of the collagen network.

This study assesses the aggregate modulus of pHEMA hydrogel as a function of ionic strength. A combined 1D confined compression and torque experiment is performed on a thin cylindrical hydrogel sample, which is brought in equilibrium with respectively $1 \mathrm{M}, 0.1 \mathrm{M}$, and $0.03 \mathrm{M} \mathrm{NaCl}$. The sample was placed in a chamber that consists of a stainless steel ring placed on a sintered glass filter, and on top a sintered glass piston. Stepwise ionic loading was cascaded by stepwise 1D compression, measuring the total stress after equilibration of the sample elucidated the diagonal terms of the aggregate elasticity tensor. In addition, a torque experiment was interweaved by applying a harmonic angular displacement and measuring the torque, revealing the relation between aggregate shear modulus and salt concentration. The difference in osmotic pressure and shear stress between two ionic loading conditions can serve to fit screening parameters of osmotic pressure and shear stress models. Potential implications for mechanotransduction are discussed.
\end{abstract}

J.M. Huyghe, R. Petterson and R.W. Roos

Eindhoven University of Technology

Department of Biomedical Engineering

Tel.: +31-(0)40-2473137

Fax: +31-(0)40-2473744

E-mail: j.m.r.huyghe@tue.nl

E-mail: r.petterson@tue.nl

E-mail: r.w.roos@gmail.com 


\section{Introduction}

In biology, presence of large ionized macromolecules has a significant influence on the mechanical properties of the extracellular matrix. This is well demonstrated in cartilage: a tissue which mainly consists of extracellular matrix and has been described as a mixture of proteoglycan-supra-molecules with a saline solution, enmeshed within a resilient collagen network (Huang et al, 2001; Jin and Grodzinsky, 2001). Whereas the stress tensor in classical elasticity would be given only by the elastic stress, the swelling analysis in charged porous media requires the use of total stress, including the (Donnan) osmotic pressure. It is well known that proteoglycans contribute significantly to the compressive modulus of articular cartilage (Maroudas, 1979) and in hydrogel this effect is shown by 1D compression-relaxation experiments (Frijns et al, 2003). Jin and Grodzinsky have shown that the shear stiffness of articular cartilage depends on ionic concentration of the environment as well (Jin and Grodzinsky, 2001). In their model, based on Poisson-Boltzmann equations, the concentration dependence of shear stiffness is explained by the double layers surrounding the proteoglycans while the effect of ion concentration on the collagen contribution to shear stiffness is neglected. Experimental evidence that water content of the collagen network is modulated by the osmotic state of the extrafibrillar compartment (Maroudas and Bannon, 1981; Urban and McMullin, 1985) seems to suggest that the shear stiffness of the collagen network may very well depend on ionic concentration. Hence, to our best knowledge, the shear stiffness as measured by Jin and Grodzinsky may be associated to ionic concentration for two reasons:

1. The double layer thickness around the proteoglycans

2. The modulation of the water content of the collagen network by the osmotic state of the extrafibrillar compartment.

In this study, we aim at circumventing the uncertainty that is introduced by the collagen, by performing experiments on a synthetic ionized gel, containing neither collagen network nor any other fiber reinforcement. Using these gels, the relationship between compressive and shear stress versus (compressive and shear) strain and ionic strengths will be investigated.

\section{Materials and method}

\subsection{Sample preparation}

The samples were made out of a hydrophilic copolymer gel of polymerized hydroxyethyl-methacrylate (HEMA) and sodium methacrylate (NaMa) monomers. The composition of the hydrogel is listed in Table 1.

\subsubsection{Preparation of monomer solution}

A bulk mixture of $1000 \mathrm{~g}$ is prepared by adding the components in the following order. First, the sodium methacrylate (NaMa) is put into hydroxy-ethyl-methacrylate (HEMA) and stirred until it is completely dissolved. Then, the demineralized water $\left(\mathrm{H}_{2} \mathrm{O}\right)$ and cross linker poly (ethylene glycol) dimethyl ether (DMPEG) are added. The solution is stirred until the DMPEG is dissolved. We put aluminium foil around the 


\begin{tabular}{|lll|}
\hline Substance & Fraction (mol \%) & $\begin{array}{l}\text { Weight per 1000 g } \\
\text { mixture }(\mathrm{g})\end{array}$ \\
\hline HEMA & 18.0 & 583.61 \\
NaMa & 2.0 & 53.86 \\
demi water & 79.9 & 358.55 \\
DMPEG & 0.20 & 3.289 \\
Initiator $^{1}$ & 0.50 & 0.676 \\
\hline
\end{tabular}

Table 1 Composition of 1000 g poly-HEMA hydrogel.

reservoir of the solution, and store the reservoir in a refrigerator at $+8^{\circ} \mathrm{C}$. The amounts of HEMA, NaMa and demi water are weighed with an electronic balance, Mettler PE 400 with an accuracy of $\pm 0.01 \mathrm{~g}$, and the amounts of DMPEG and of 4,4 Azobis(2methylpropanamide)dichloride are weighed with a more sensitive electronic balance: Mettler PE 200 with an accuracy of $\pm 0.0001 \mathrm{~g}$. Every time the solution is polymerized only part of it is used.

\subsubsection{Polymerizing the mixture in the right shape}

A special mould is designed to prepare a disc shaped hydrogel sample (Fig. 1). The mould bottom is an ertalite piston which can be screwed up and down to adjust the initial sample thickness between $1 \mathrm{~mm}$ and $10 \mathrm{~mm}$. A thin Teflon plate on top of the piston, facilitates the sample release from the mould bottom after polymerization. The UV-sensitive initiator (4,4'-Azobis(2-methylproprionamidine)-dihydrochloride) is dissolved in ample bulk monomer mixture by putting them in an ultrasone bath for about 15 minutes. After it is dissolved, it is poured in this tapered mould. Now, a glass plate is placed on top of the sample chamber without entrapping air bubbles. After the

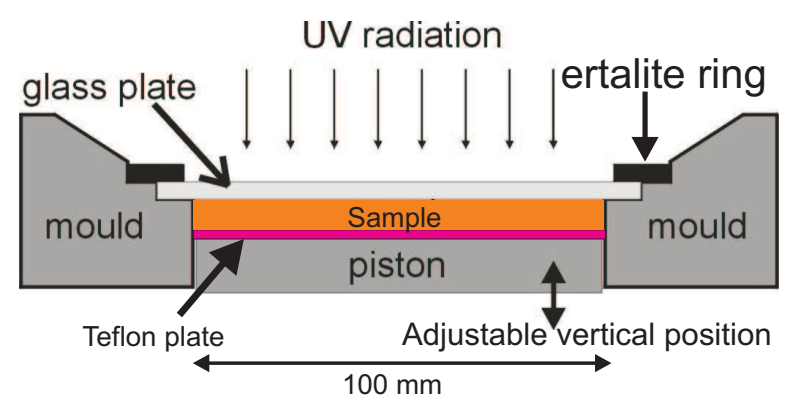

Fig. 1 The mould in which the hydrogel sample was prepared. The sample thickness is tunable by screwing the piston, with a $100 \mathrm{~mm}$ diameter and a Teflon plate on top. After a surplus of monomer mixture, mixed with a UV-sensitive initiator (4,4 Azobis(2methylpropanamide)dichloride), is poured into the mould, a glass plate confines the sample. This plate is clamped by an ertalite ring. After the superfluous mixture solution is thrown away, a UV radiation source induces the polymerization.

glass plate is clamped by an ertalite ring, the superfluous mixture solution is thrown away and a $440 \mathrm{~W}$ longwave ultraviolet-lamp is placed $30 \mathrm{~cm}$ above the mould. Within 90 minutes, the mixture is polymerized and the hydrogel is carefully taken from the mould. Then, it is placed in a $1 \mathrm{M} \mathrm{NaCl}$ solution for at least one week. The first week, 
the solution is refreshed every other day to wash the gel from unreacted monomers and initiator remains. When the sample is settled to its new equilibrium, a $100 \mathrm{~mm}$ disc is cut from the swollen sample and its weight is determined. The plan-parallellity of the sample surface is $0.6 \mathrm{mrad} / \mathrm{m}$, which corresponds with $60 \mu \mathrm{m}$ of sample thickness variation across the sample.

\subsection{Experimental set-up}

The sample is placed in a specially designed chamber, surrounded by a Polymethylmetacrylate tank, filled with a $\mathrm{NaCl}$ solution at constant temperature (Fig. 2). This chamber consists of three separate parts: the bottom, a stainless steel ring, and a piston which fits without friction in the ring. To both bottom and piston, cylindrical sintered glass filters with a pore size between 16 and $40 \mu \mathrm{m}$ are glued. The bottom filter is glued at a few spots in a solid stainless steel holder, which is attached to a MTS 662.20D-04 load transducer which measures both axial and torque load. Similarly, the piston filter is glued to a solid stainless steel holder, which is connected to a torsional and axial actuator: MTS-858 Mini Bionix draw-torsion bench (MTS, Minneapolis-Saint Paul, MN, USA). The piston glass filter has a $100 \mathrm{~mm}$ diameter and is $4 \mathrm{~mm}$ thick, while the filter at the bottom has a $150 \mathrm{~mm}$ diameter and is $3 \mathrm{~mm}$ thick. These porous filters enable fast exchange of solutes between the sample and the surrounding bathing solution, while at the same time they vertically clamp the sample. We measured in this setup a filter-filter plan-parallellity of $2.8 \mathrm{mrad} / \mathrm{m}$, which corresponds with a maximum of $280 \mu \mathrm{m}$ variation across the sample. The sample is placed between the two filters in such a way, that the skewness of the sample is partly cancelled out by the angle between the two filters. Small holes inside the sample holder and piston ensure constant physical contact between the sintered glass plates and the surrounding bath.

Finally, a $10 \mathrm{~mm}$ thick stainless steel ring, with $100 \mathrm{~mm}$ inner diameter, is axially centred and clamped to the bottom filter. The ring consists of two parts: the inner ring and the outer ring. The outer ring fixates the inner ring on the bottom filter, to minimize sample swelling under this ring.

\subsubsection{Prevention of corrosion}

Corrosion of the setup in the saline solution affects the fixed charge concentration of the sample, and therefore has to be avoided. Therefore, all parts of the assembled measurement setup are made of stainless steel (SAE grade: 316, or X5CrNiMo17-12-2). In addition, all parts of the measurement equipment that come in contact with (or are placed in the vicinity of) the saline solution, are treated with a coating as an extra protection. After all parts are degreased, sandblasted and degreased again, a thin layer of 2 component primer Epoxy GP coating (Sikkens), is applied with an airbrush within two hours. After this primer has dried, 5 layers of Epoxy Barrier Coat GP are applied. Between each layer, the coating dried for 1 day. After the last layer is applied, the coating is cured for one week before it is placed in water.

\subsubsection{Local measurement of piston position.}

The position of the piston on top of the sample determines the thickness of the sample. Under the expected loads (up to $10 \mathrm{kN}$ ), deformation of the draw bench introduces 


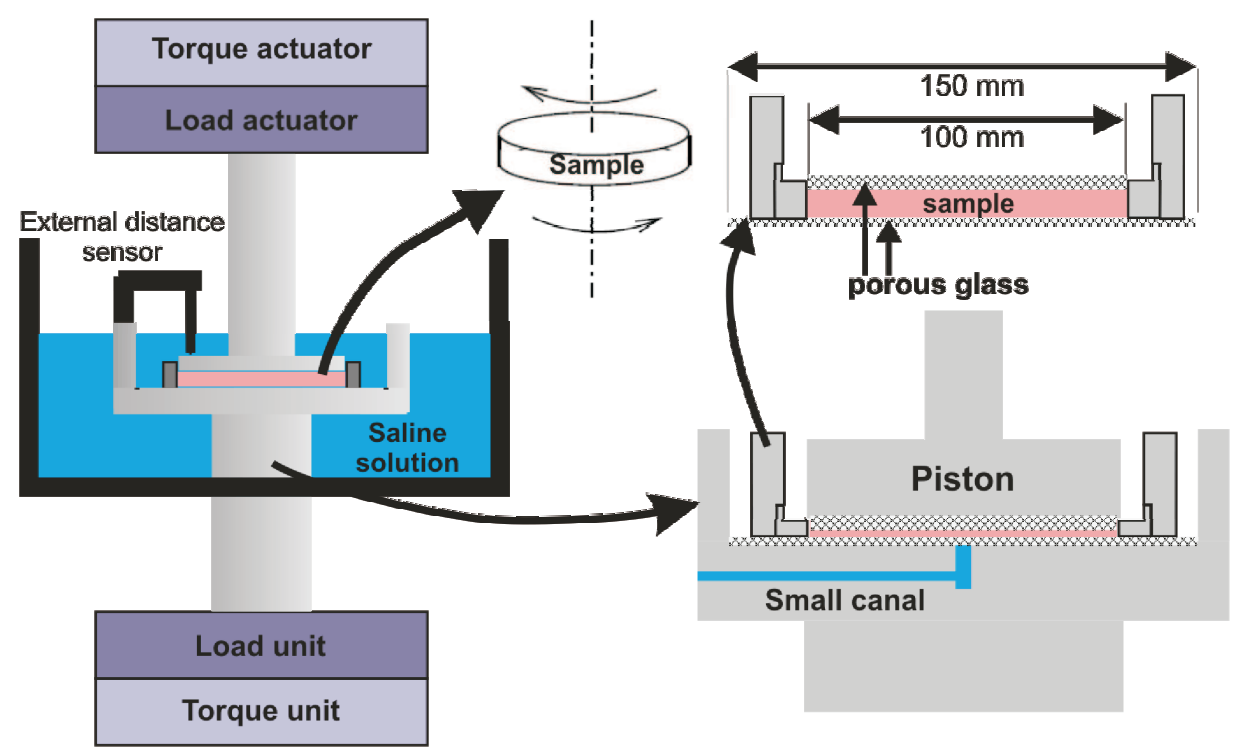

Fig. 2 Drawings of the setup of the strain- torque experiments. Left: Overall view. Right: detailed view around the sample. The setup is placed within a 10 liter bath reservoir which is temperature controlled at $25^{\circ} \mathrm{C}$, with $0.1^{\circ} \mathrm{C}$ accuracy. It is placed on top of both an axial load unit and a torsional load unit. The upper platen is controlled in axial- and angular direction by a hydraulic MTS-Bionix draw torsion bench.

a mismatch between the given value of the piston height, and the actual height in the order of several millimetres. Therefore, the piston height is measured locally with an external linear variable distance transducer (LVDT): Schaevitz AC-LVDT CD 375, which has a measurement range of $\pm 4 \mathrm{~mm}$ and a maximum linearity error of $10 \mu \mathrm{m}$ (Fig. 2, left). The load actuator of the draw torsion bench is tuned to the output signal of this LVDT.

\subsubsection{Correction of angular displacement.}

We choose to load the sample dynamically, because for small angular strains the expected torque will be within be smaller than the torque noise of $0.05 \mathrm{Nm}$. The torsional compliance of the measurement system is not infinite. Therefore, the torsional compliance $\left(\frac{\alpha}{M}\right)_{\text {setup }}$ of the setup system itself is measured, by connecting the upper plate with the torque unit via a (stiff) metal plate of $10 \mathrm{~cm}$ diameter and $2 \mathrm{~cm}$ thickness. The torque-unit measures the linear response of the setup to the actuated angular displacements between $\left[-0.2^{\circ}\right.$ and $\left.0.1^{\circ}\right]$ :

$$
\left(\frac{\alpha}{M}\right)_{\text {setup }}=0.39110^{-3}\left(\operatorname{radN}^{-1} \mathrm{~m}^{-1}\right)
$$

where $M$ is the measured torque (Nm). This extra angle has to be subtracted from the total applied angle:

$$
\alpha_{\mathrm{s}}=\alpha_{\text {applied }}-\alpha_{\text {setup }}
$$




\subsection{Calculation methods}

The sample configuration after placement in the measurement setup is regarded as the reference configuration. Then the sample is subject to a $1 \mathrm{D}$ confined compression experiment in the $z$-direction, with an interweaved torque experiment with an amplitude $\alpha_{s}\left(^{o}\right)$ angular displacement at the upper sample surface.

$$
F=\left[\begin{array}{ccc}
1 & 0 & 0 \\
0 & 1 & 0 \\
0 & \frac{r \alpha_{s}}{h_{s}} & \frac{h_{s}}{h_{r e f}}
\end{array}\right]
$$

where $r$ is the radial position $[\mathrm{m}]$ and $h$ is the sample thickness. The subscript $s$ refers to the sample and the subscript ref refers to the reference configuration. The successive rows and columns of the matrices are associated with the radial, circumferential and axial direction respectively. From this deformation tensor we derive the left CauchyGreen strain tensor:

$$
F F^{c}=\left[\begin{array}{ccc}
1 & 0 & 0 \\
0 & 1 & \frac{r \alpha_{s}}{h_{s}} \\
0 & \frac{r \alpha_{s}}{h_{s}} & \left(\frac{r^{2} \alpha_{s}^{2}}{h_{s}^{2}}+\frac{h_{s}^{2}}{h_{1}^{2}}\right)
\end{array}\right]
$$

We use this to calculate the Green strain $\epsilon_{c g}$ at each stage of the experiment:

$$
\epsilon_{c g}=\frac{1}{2}\left(F F^{c}-I\right)
$$

More specifically, we can extract the $z$-component from the Green strain tensor:

$$
\epsilon_{\mathrm{cg}}^{z}=\frac{1}{2}\left[\left(\frac{r \alpha_{s}}{h_{s}}\right)^{2}+\left(\frac{h_{s}}{h_{r e f}}\right)^{2}-1\right],
$$

and also the shear term:

$$
\epsilon_{\mathrm{cg}}^{\alpha}(r)=\frac{r \alpha_{s}}{2 h_{s}}
$$

Now, the torque $M_{s}[\mathrm{~N} \mathrm{~m}]$ can be calculated by integration of the shear strain across the sample radius $R[\mathrm{~m}]$ :

$$
M_{s}=\int_{0}^{R} 2 \epsilon_{c g}^{\alpha}(r) G_{s}^{e f f} r 2 \pi r \mathrm{dr}=\frac{\pi \alpha_{s} R^{4}}{2 h_{s}} G_{s}^{e f f}
$$

It can be shown that this effective shear modulus - $G_{s}^{\text {eff }}\left[\mathrm{Nm}^{-2}\right]$ - is related to the fraction $M_{s} / \alpha_{s}$ :

$$
G_{s}^{e f f}=\frac{2 h_{s}}{\pi R^{4}} \frac{M_{s}}{\alpha_{s}} .
$$




\subsection{Measurement protocol}

\subsubsection{Experiment start up}

Before all parts of the measurement system are installed, they are cleaned with water and soap and rinsed with water. Then, the entire setup is cleaned with air. A ring is placed on the bottom filter and centered such that it exactly fits around the upper piston filter, forming together the sample chamber (Fig. 2, left). After the axial position of the Bionix is calibrated at zero sample thickness, the sample is placed in the chamber and the piston is descended until the piston filter has full contact with the sample. This sample thickness at the start of the experiment equals $h_{s}=2.44 \mathrm{~mm}$. Finally, the surrounding compartment is filled with a $1 \mathrm{M} \mathrm{NaCl}$ solution.

\subsubsection{Measurement sequence}

A combined compression-torque experiment on a disc shaped pHEMA hydrogel sample is performed at different bathing concentrations (Fig. 3). All combinations of molarity, axial load and angular load are measured in two recursive loops. At each concentration level, a confined compression experiment is performed with a torque experiment at each strain level, when the sample is in its new equilibrium. Furthermore, the confined compression experiment includes both increasing and decreasing compression steps. Starting at $1 \mathrm{M} \mathrm{NaCl}$, the salt solution decreases via $0.1 \mathrm{M} \mathrm{NaCl}$ to $0.03 \mathrm{M} \mathrm{NaCl}$.

\subsubsection{Confined compression}

The sample is pre-compressed to $2.19 \mathrm{~mm}$ (starting point of compression experiment) at $1 \mathrm{M} \mathrm{NaCl}$ and equilibrates for 17 hours. Now, a confined compression experiment is performed where the sample is compressed $0.5 \mathrm{~mm}$, in steps of $0.1 \mathrm{~mm}$. After each step, the sample equilibrates for about 5 hours and a torque experiment is carried out (Fig. 5). After the highest compression state, the same path of compressed states is followed backwards, in order to check the effect of the route on the measured stress or shear stiffness of the sample.

When the sample is back in its original configuration, the sodium concentration is changed to $0.1 \mathrm{M} \mathrm{NaCl}$. The sample was allowed to swell because we noticed that this accelerated the equilibration rate, and the sample reached its new equilibrium within 4 days, with $h_{s}$ increased to $2.98 \mathrm{~mm}$. Therefore, the confined compression experiments at $0.1 \mathrm{M} \mathrm{NaCl}$ and at $0.03 \mathrm{M} \mathrm{NaCl}$ were extended with 9 extra steps, where the highest 6 sample compression states correspond with the compression states at $1 \mathrm{M}$ $\mathrm{NaCl}$ (Fig. 3).

\subsubsection{Torque experiment}

The piston rotates harmonically at a frequency of $0.1 \mathrm{~Hz}$, with three different amplitudes: $0.1^{\circ}, 0.2^{\circ}$ and $0.3^{\circ}$. Because we assume that a thin water film between the sample and the confining ring causes frictionless movement of the border of the sample, we can directly deduce sample shear stiffness from the measured torque and angular displacement, using expressions (1),(2) and (9). 


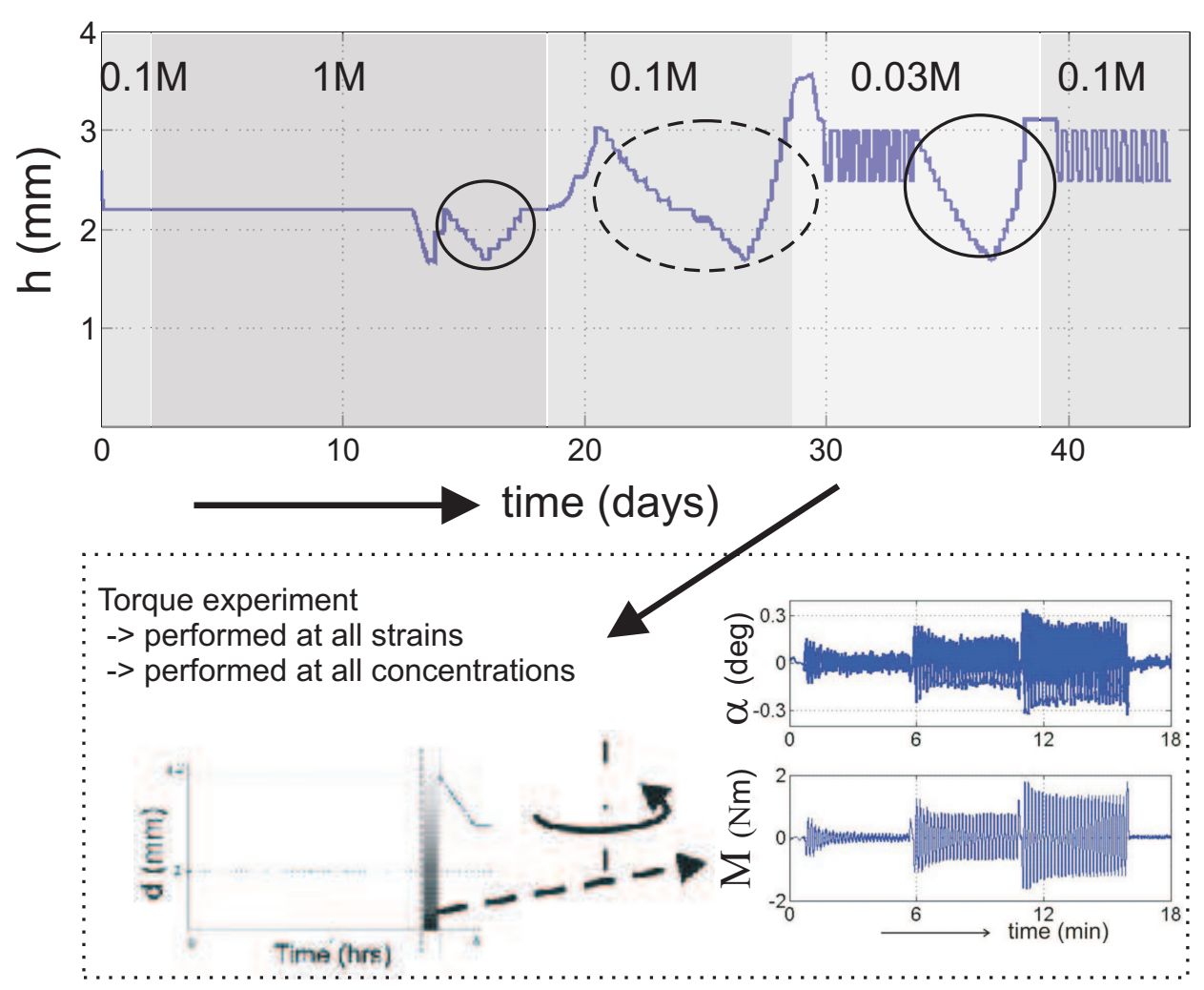

Fig. 3 A chronological sketch of the compression-torque experiment on a $2 \mathrm{~mm}$ thick hydrogel disk with $100 \mathrm{~mm}$ diameter. The compression-torque experiment is subsequently carried out at bath concentrations of $1 \mathrm{M}, 0.1 \mathrm{M}$ and $0.03 \mathrm{M} \mathrm{NaCl}$. In addition, the stepwise replacement of the bath concentrations is cascaded with stepwise compression and harmonic shear loading of the sample. During the compression experiments, the sample is subsequently compressed in steps of $0.1 \mathrm{~mm}$, and after reaching the minimum thickness of $1.79 \mathrm{~mm}$, the sample is stepwise released the same route. At $1 \mathrm{M} \mathrm{NaCl}$ bath concentration, the compression experiment starts at $2.19 \mathrm{~mm}$ sample thickness, but at $0.1 \mathrm{M} \mathrm{NaCl}$ and $0.03 \mathrm{M} \mathrm{NaCl}$ bath concentration the compression experiment starts at $2.99 \mathrm{~mm}$. To ensure overlap with the $1 \mathrm{M} \mathrm{NaCl}$ experiment, the lowest sample thickness is the same for all three experiments. In the torque experiment, three steps in amplitude are applied: $0.1^{\circ}, 0.2^{\circ}$ and $0.3^{\circ}$, where the shear strain is always less than 5\%.

\section{Results}

\subsection{Confined compression experiment}

We have performed confined compression-relaxation experiments on a disc shaped pHEMA-hydrogel sample that was equilibrated at respectively $1 \mathrm{M}, 0.1 \mathrm{M}$ and $0.03 \mathrm{M}$ $\mathrm{NaCl}$. The result of these measurements in their exact chronological order is shown in Fig. 4.

For all compression states, the sample almost reaches its new equilibrium state within 6 hours (Fig. 5). Comparison of the compression - relaxation curves of $0.1 \mathrm{M}$ $\mathrm{NaCl}$ and $0.03 \mathrm{M} \mathrm{NaCl}$ displays similar equilibrium pressure values but a difference in 


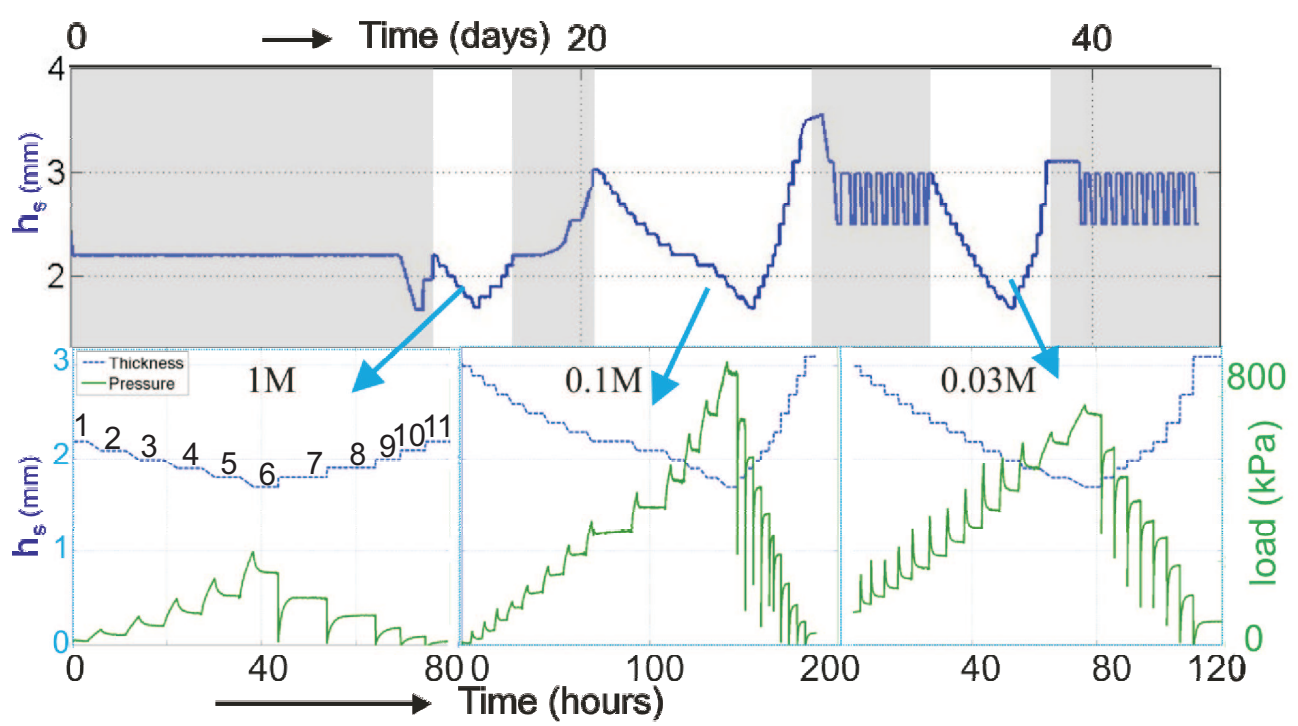

Fig. 4 The confined compression experiments at a $1 \mathrm{M} \mathrm{NaCl}$ (left), $0.1 \mathrm{M} \mathrm{NaCl}$ (middle) and $0.03 \mathrm{M} \mathrm{NaCl}$ bath solution (right). At small strains, the equilibrium load values during mechanical loading and unloading differ less than $3 \%$, and the equilibrium load values during loading are consistently lower compared to the corresponding values during unloading.

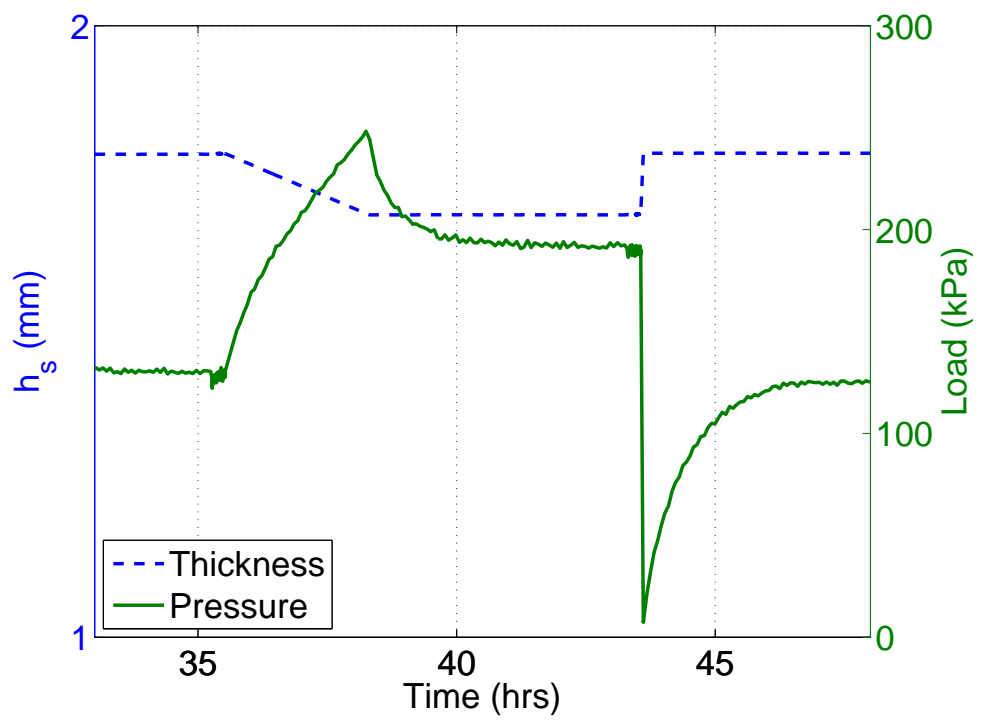

Fig. 5 A detail of the stress consolidation curve at $1 \mathrm{M} \mathrm{NaCl}$ (Fig. 4): the settlement of the stress after the sample has been compressed to the lowest compressive state. It takes about five hours to settle to an equilibrium that correspond with a new compressed state.

overshoot values during the mechanical loading phase and unloading phases (with the 
same applied vertical piston speed). However, the piston speed was not the same in both experiments and no conclusions can be drawn from this difference.

\subsubsection{Reproducibility confined compression}

We verify sample equilibria by comparing the final load values of the mechanical loading trajectory with the mechanical unloading trajectory. Fig. 4 shows that the pressure equilibrium plateaus are approached from above during the mechanical loading phase and from beneath during the mechanical unloading phase. A measure for reproducibility at all bath concentrations is given in Table 2. We see in the raw data of Fig. 4 that at $1 \mathrm{M} \mathrm{NaCl}$ bath concentration the difference between both routes is consequently $4 \mathrm{kPa}$, which is only $2 \%$ at $1.7 \mathrm{~mm}$ sample thickness. At $0.1 \mathrm{M} \mathrm{NaCl}$, the pressure difference between corresponding sample thicknesses has increased to about $10 \mathrm{kPa}$. In this measurement sequence, the first 7 equilibrium states display a small increase in pressure after mechanical equilibrium has been accomplished (Fig. 4). This might be caused by unfinished chemical settlement of the sample during this part of the confined compression experiment, leading to an underestimation of the equilibrium values in the loading phase, and hence an inverted pressure difference above sample thicknesses of $2.2 \mathrm{~mm}$. Finally, the compression - relaxation curve at $0.03 \mathrm{M} \mathrm{NaCl}$ is almost the same as for $0.1 \mathrm{M} \mathrm{NaCl}$. Only now, the variation within two corresponding states has increased to $20 \mathrm{kPa}$; especially at large sample thicknesses. The pressure values for all equilibrium plateaus at different mechanical loading and ionic loading stages are assembled as a function of Green strain in Fig. 6.

Table 2 An overview of maximum pressure deviations between corresponding states at different bath solutions.

\begin{tabular}{ccl} 
Bath conc. & $\Delta P_{\max }$ & Remark \\
\hline $1 \mathrm{M}$ & $4 \mathrm{kPa}$ & Equilibrium almost attained \\
$0.1 \mathrm{M}$ & $\begin{array}{l}10 \mathrm{kPa} \\
50 \mathrm{kPa}\end{array}$ & $\begin{array}{l}\text { For same sample thicknesses as at } 1 \mathrm{M} ; h_{s}<2.2 \mathrm{~mm}, \text { the compress trajectory } \\
\text { always yields lower values } \\
\text { The sample may be affected by corrosion of the set-up }\end{array}$ \\
& $20 \mathrm{kPa}$ & $\begin{array}{l}\text { The } \\
0.03 \mathrm{M}\end{array}$
\end{tabular}

During the measurement of the final bath concentration $(0.03 \mathrm{M} \mathrm{NaCl})$, despite our precautions, the salt bath coloured brown as a consequence of an oxidation process of the stainless steel measurement setup. When we dismantled the setup, we noticed that the sample itself displayed overall a decreased transparency (Fig. 7). So at least a thin layer of $1 \mathrm{~mm}$ at the outside radius of the sample was affected by the impurity of $\mathrm{Fe}^{2+}$ and $\mathrm{Fe}^{3+}$ ions. Nevertheless, equilibrium loads at given strains along the compression and decompression sequences, seems very close to eachother at all three concentration (Fig. 4). This is so, despite the long periods - up to 100 hours - that elapsed between those eqilibrium states. 


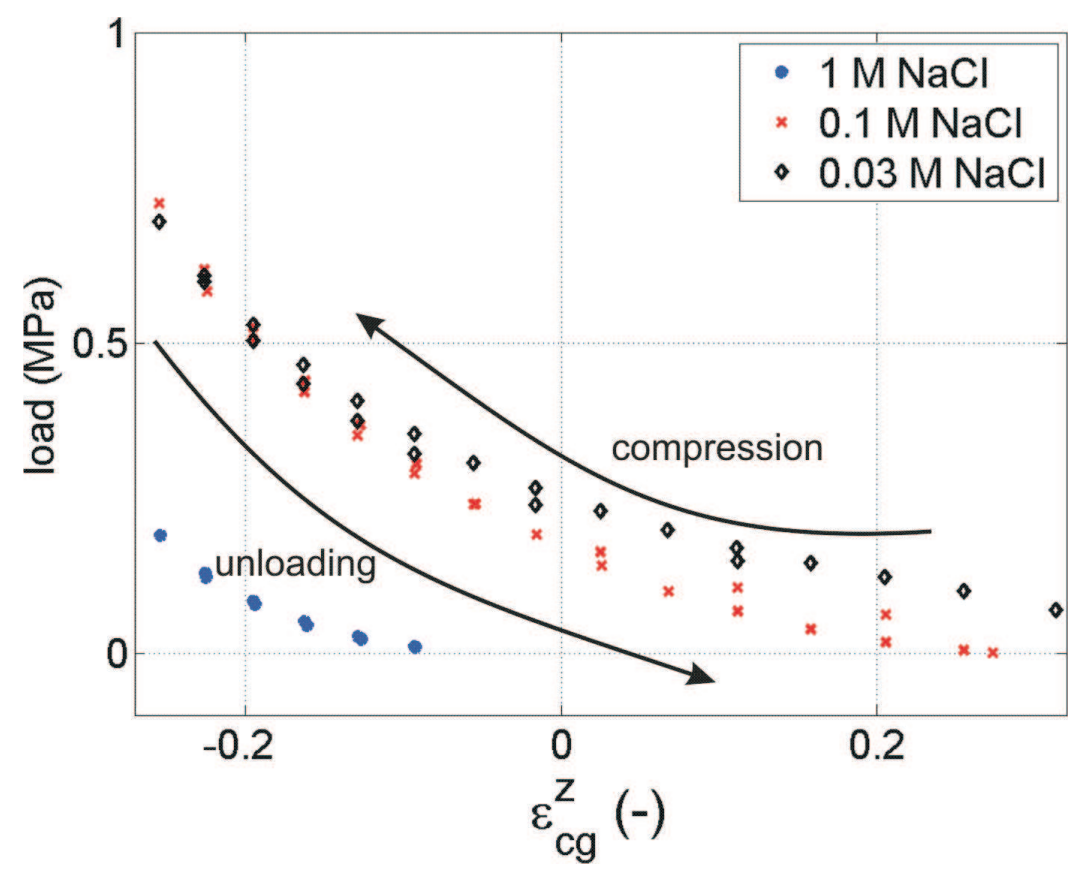

Fig. 6 The results of all equilibrium stages of the performed compression experiments at $1 \mathrm{M}$, $0.1 \mathrm{M}$ and $0.03 \mathrm{M} \mathrm{NaCl}$ solution. At the same compressive state, different loads are measured for different ionic concentrations.

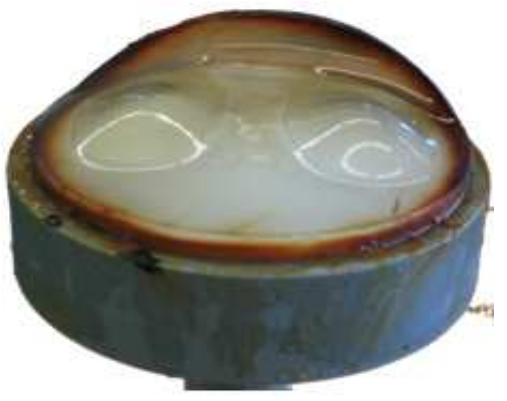

Fig. 7 After the measurement series, the outside radius of the sample has been affected by corrosion of stainless steel. Dissolved iron ions $\left(\mathrm{Fe}^{2+}\right.$ or $\left.\mathrm{Fe}^{3+}\right)$ bind to the ionized groups (fixed charges) of the polymer gel, leading effectively to a decreased fixed charge density in the outer shell of the sample. 


\subsection{Shear experiment}

As mentioned in the previous sections, a shear experiment was recursively weaved into the confined compression experiments. Each time a new stress state was reached, a torque experiment is performed. We apply a sine function with three different angular strain amplitudes as described in $\S 2.4 .4$ and measure the torque response. After correction of angular displacement of the setup, we obtain angular sample displacement and corresponding sample torque responses (Fig. 8). Even at the largest angular amplitude $0.3^{\circ}$, at the smallest sample thickness, the shear strain (7) at the periphery of the sample is always less than $5 \%$.

In Fig. 8 and Fig. 9 we see that the actual realised angular amplitude curve starts at the actuated level $\left(0.1^{\circ}, 0.2^{o}\right.$ and $\left.0.3^{\circ}\right)$, but than drops to a steady state level with a smaller amplitude after approximately 10 cycles. Therefore, the first 10 cycles will be left out of our analysis. We filter the high frequencies from the remaining data with a Butterworth filter and fit a sine function to the result by means of the least squares method. This dynamic settlement and filtering/fitting is shown in detail in Fig. 9, and yields the angular and torque amplitude for all compression states and all ionic concentrations. The different compression states of the sample are translated to a difference in angular strain via the sample thickness in the expression (7). This means that at the same applied angular displacement, angular strain decreases with larger sample thicknesses. In Fig. 10, the torque is plotted as a function of angular strain $\epsilon_{c g}^{\alpha}$, where the numbers 1-11 correspond to the equilibrium states as shown in Fig. 4.
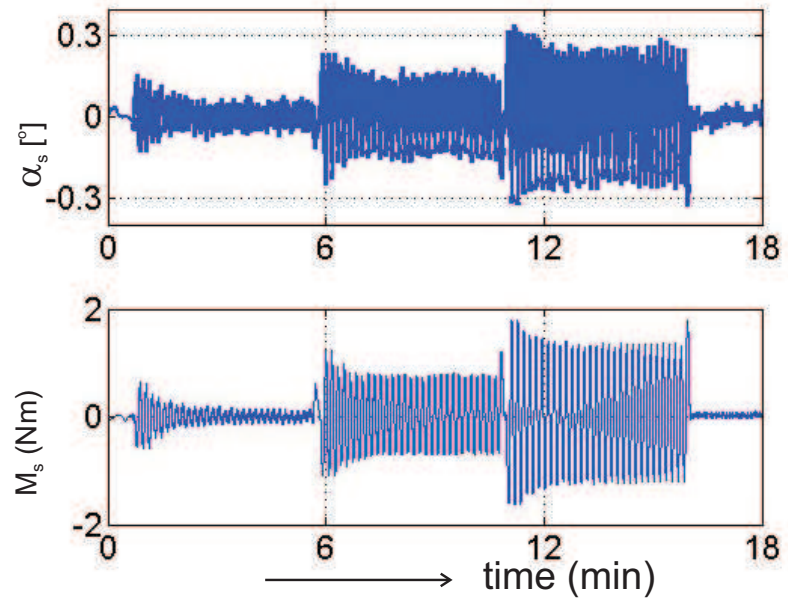

Fig. 8 An example of the harmonic angular displacement and the sample torque after correction for displacement of the setup at a bath concentration of $0.1 \mathrm{M} \mathrm{NaCl}$, and sample thickness of $2.09 \mathrm{~mm}$. Three different shear loads have been applied at each torque experiment. 

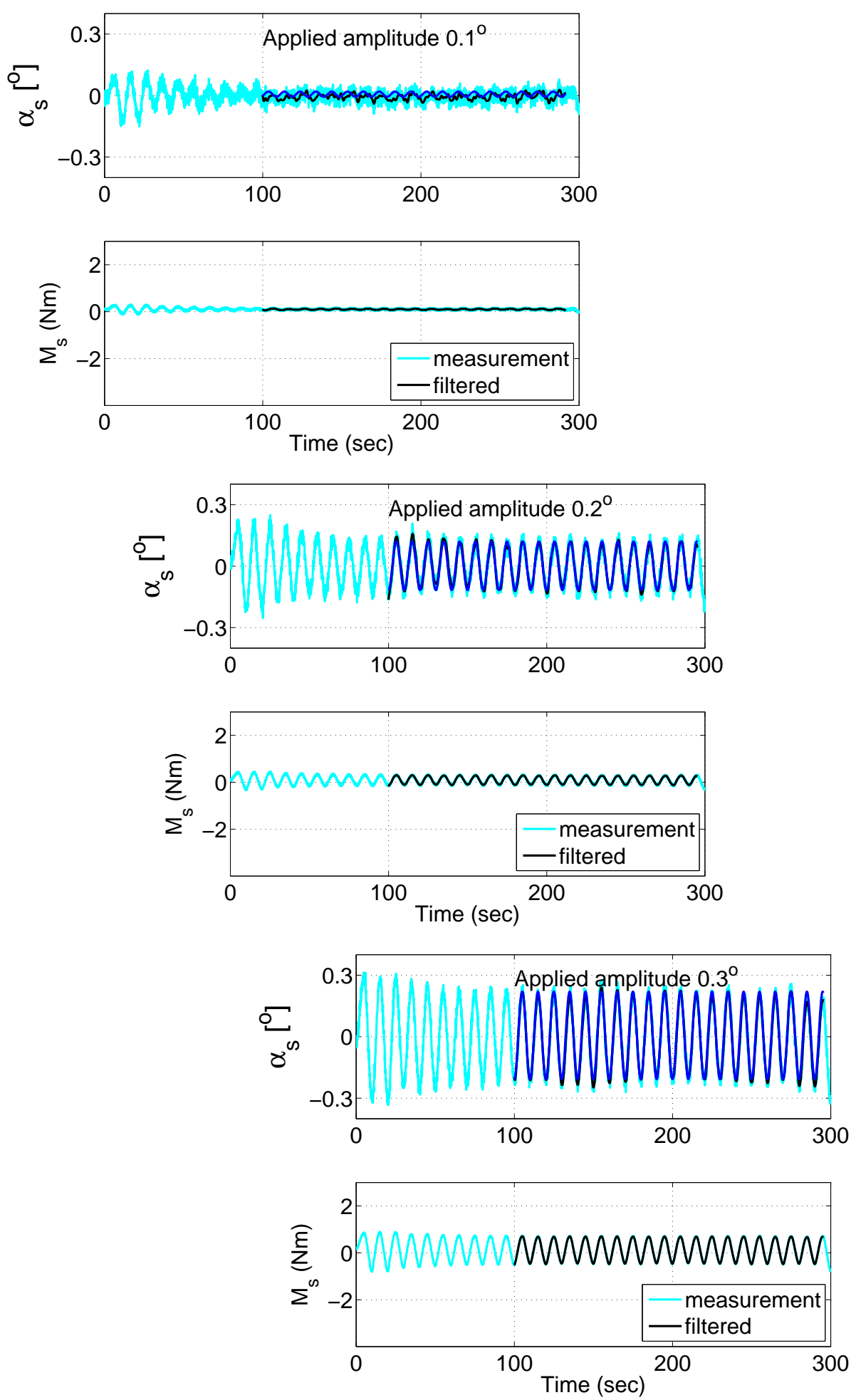

Fig. 9 As an example the angular displacement and the measured torque of the sample (after correction for displacement of the setup) are displayed for all applied angular amplitudes at a particular load $(\hat{c}=1 \mathrm{M} \mathrm{NaCl}$ and $h=2.19 \mathrm{~mm})$. Each angular load settles towards a dynamic equilibrium with a lower amplitude than actuated. Only after the first 10 cycles, the curves are filtered and fitted to a sine function to determine the amplitude of $\alpha_{s}$ and $M_{s}$. The S/N ratio increases for higher angular displacements. 


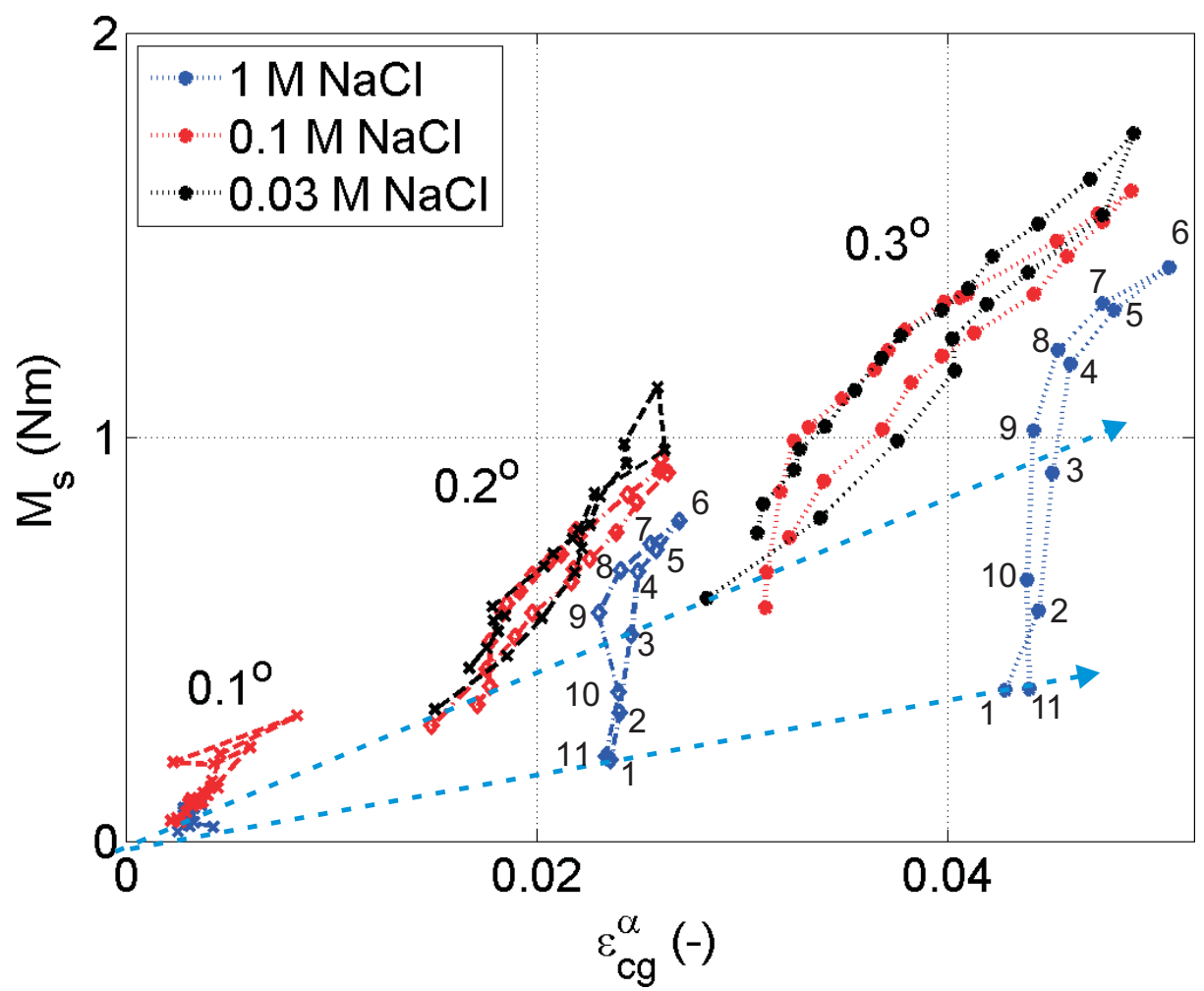

Fig. 10 The torque versus the angular strain at different compaction states, for different ionic loads and an actuated angular amplitudes of $0.1^{\circ}, 0.2^{\circ}$ and $0.3^{\circ}$. The angular strain is based on the measured amplitude when the sample is in dynamic equilibrium (7), which depends on sample thickness: at the same applied angular displacement, angular strain decreases with larger sample thicknesses. The loops associated with different angular displacements result in different angular strains and moments, but corresponding points on each of the loops have moment to angular strain ratio's $\left(M_{s} / \alpha_{s}\right)$ which are consistent (dotted arrows). The loops consistently follow an anti-clockwise path, as indicated by the numbers 1 - 11 which correspond with the compression states in Fig. 4, left under. 


\section{Discussion}

To our best knowledge, this is the first study demonstrating that the shear modulus of a pHEMA hydrogel at a given strain depends on ionic concentration. The combination of confined compression and torque enables us to provide strong evidence for this hypothesis. The result is consistent with similar experimental findings in cartilage (Jin and Grodzinsky, 2001) and with Poisson-Boltzmann simulations of shearing double layers around ionized rods that indicate a similar trend (Jin and Grodzinsky, 2001). Besides the results in shear modulus, the experimental data gathered during this experiment provides a wealth of data that may be used to model the chemomechanical response of hydrogels.

\subsection{Confined compression}

Fig. 6 illustrates the equilibrium load-compression relationship, during the experiments. The loads after mechanical loading are less than $3 \%$ lower than the states after mechanical unloading, indicating that the equilibrium stages are reasonably reproducible. Despite the fact that the sample seems visually affected by corrosion of the coated stainless steel measurement setup (Fig. 7), the equilibria are reproducible up to the end of the experiment. The equilibration period after mechanical loading and unloading is in the order of 2 hours, leading to a pressure diffusion coefficient in the order of $10^{-10}\left[\mathrm{~m}^{2} \mathrm{sec}^{-1}\right]$. The positive load peaks after the compressive ramps and the negative peaks after the unloading ramps are qualitatively explained by standard consolidation theory. The strong variability of the peak may be associated with non-linearity of the constitutive equations.

\subsection{Shear experiments}

The curves of Fig. 10 show that all applied angular amplitude sequences consistently follow a anti-clockwise path, indicating that the torque moment at a certain actuated load is higher during mechanical loading (from left to right) than during mechanical unloading (from right to left). This difference is possibly associated with the incomplete stage in which equilibrium has been reached after axial loading and unloading at the time of the shear experiments. Furthermore, we notice that at $1 \mathrm{M} \mathrm{NaCl}$, the curve is very steep during the first compression states, and less steep at the most compressed sample configurations. This typical shape is consistent for both the angular load of $0.2^{\circ}$ amplitude, as for the angular load of $0.3^{\circ}$ amplitude (Fig. 10).

For all actuated angular amplitudes, the fraction $M_{s} / \alpha_{s}$ is close to constant. We can calculate the shear modulus for each bath concentration and each compression state with (9), and display the results as a function of $\epsilon_{c g}^{z}$ (Fig. 11):

\subsection{Mechanotransduction}

The experimental data show that off-diagonal terms of

$$
\sigma=J F \cdot \frac{\partial W}{\partial \epsilon_{c g}} \cdot F^{c}-\pi I
$$




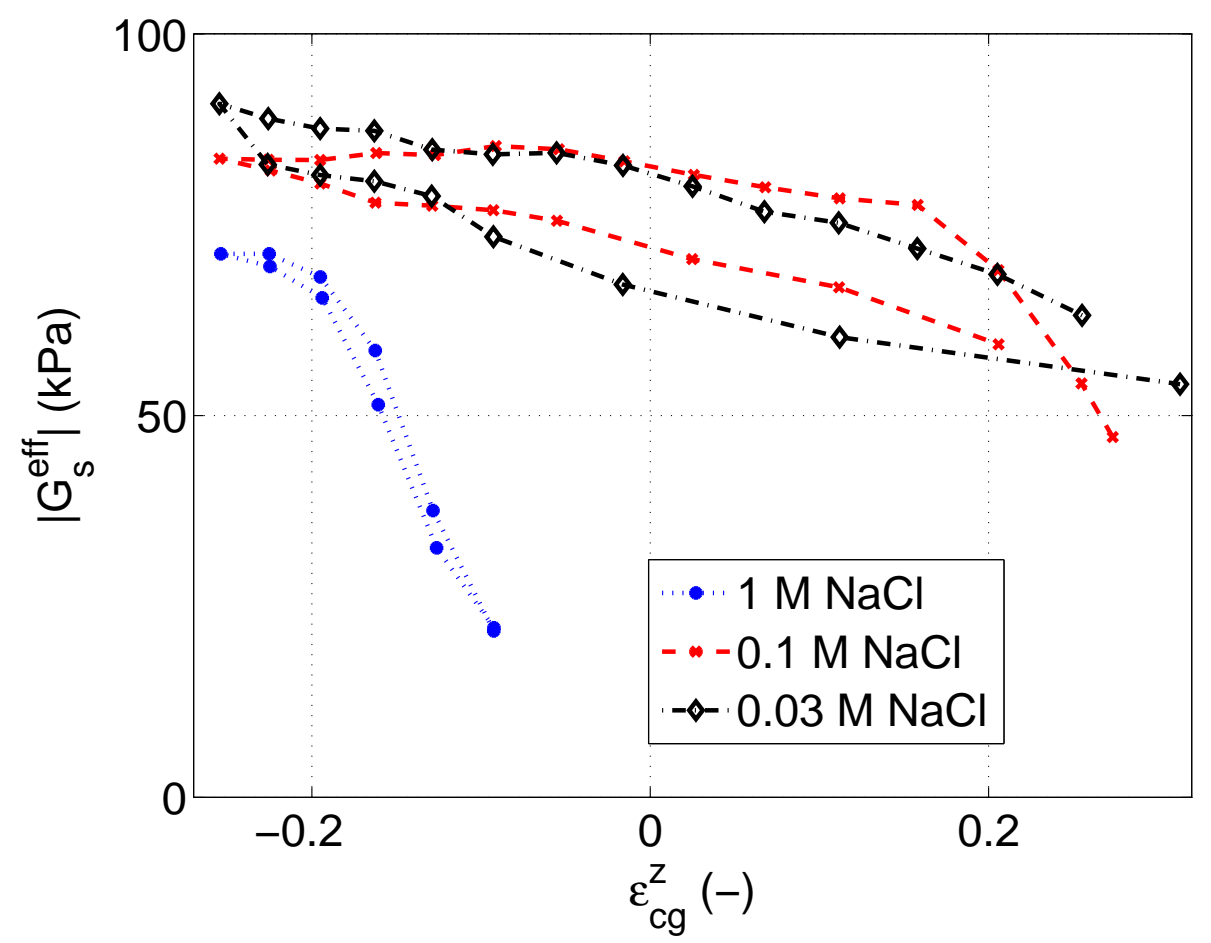

Fig. 11 The effective shear modulus as a function of Green strain for each bath concentration. The curves consistently follow a anti-clockwise path.

are dependent on ionic concentration, even if the strain is kept constant. Hence, the shear stress $\frac{\partial W}{\partial \epsilon_{c g}^{\alpha}}$ of the gel should depend explicitly on ionic concentration. This result implies that:

$$
\frac{\partial W^{2}}{\partial c^{+} \partial \epsilon_{c g}^{\alpha}} \neq 0 \quad \text { and /or } \frac{\partial W^{2}}{\partial c^{-} \partial \epsilon_{c g}^{\alpha}} \neq 0
$$

The electrochemical potentials of both ion species:

$$
\begin{aligned}
& \mu^{+}=\mu_{0}^{+}+p \overline{V^{+}}+\frac{\partial W}{\partial c^{+}}+F \xi \\
& \mu^{-}=\mu_{0}^{-}+p \overline{V^{-}}+\frac{\partial W}{\partial c^{-}}-F \xi
\end{aligned}
$$

should depend on strain:

$$
\frac{\partial \mu^{+}}{\partial \epsilon_{c g}^{\alpha}} \neq 0 \quad \text { and/or } \frac{\partial \mu^{-}}{\partial \epsilon_{c g}^{\alpha}} \neq 0,
$$

suggesting that a shear deformation should induce ionic fluxes. This mechanism may be an explanation of mechanotransduction observed in many tissues (Burger et al, 1998; Wang et al, 1993; Sikavitsas et al, 2001; Szafranski et al, 2004; Dalby, 2005; Iqbal and Zaidi, 2005; Orr et al, 2006; Papachroni et al, 2009). 
Acknowledgements This research is supported by the technology foundation STW, applied science division of NWO, and the technology programs of the Ministry of Economics. The authors thank Alan Grodzinsky (MIT, Boston, MA) and Gerard Ateshian (Columbia University, New York, NY) for fruitful discussions on this subject.

\section{References}

Burger EH, Klein-Nulend J, Cowin SC (1998) Mechanotransduction in bone. In: Molecular and Cellular Biology of Bone, Advances in Organ Biology, vol 5, Elsevier, pp $123-136$

Dalby MJ (2005) Topographically induced direct cell mechanotransduction. Medical Engineering \& Physics 27(9):730 - 742, this issue contains a special section on Effects of Mechanical Forces Engineering Reactions at the Cellular Level

Frijns AJH, Huyghe JM, Kaasschieter EF, Wijlaars MW (2003) Numerical simulation of deformations and electrical potentials in a cartilage substitute. Biorheology 40(13):123-131

Huang CY, Mow VC, Ateshian GA (2001) The role of flow-independent viscoelasticity in the biphasic tensile and compressive responses of articular cartilage. Journal of biomechanical engineering 123(5):410-417

Iqbal J, Zaidi M (2005) Molecular regulation of mechanotransduction. Biochemical and Biophysical Research Communications 328(3):751 - 755, vertebrate Skeletal Biology

Jin M, Grodzinsky AJ (2001) Effect of electrostatic interactions between glycosaminoglycans on the shear stiffness of cartilage: A molecular model and experiments. Macromolecules 34:8330-8339

Maroudas A, Bannon C (1981) Measurement of swelling pressure in cartilage and comparison with the osmotic pressure of constituent proteoglycans. Biorheology 18(36):619-632

Maroudas A (1979) Physicochemical properties of articular cartilage. In: Freeman M (ed) Adult articular cartilage, Pitman Medical, London, UK, pp 215-290

Orr AW, Helmke BP, Blackman BR, Schwartz MA (2006) Mechanisms of mechanotransduction. Developmental Cell 10(1):11 - 20

Papachroni KK, Karatzas DN, Papavassiliou KA, Basdra EK, Papavassiliou AG (2009) Mechanotransduction in osteoblast regulation and bone disease. Trends in Molecular Medicine 15(5):208 - 216

Sikavitsas VI, Temenoff JS, Mikos AG (2001) Biomaterials and bone mechanotransduction. Biomaterials 22(19):2581 - 2593

Szafranski JD, Grodzinsky AJ, Burger E, Gaschen V, Hung HH, Hunziker EB (2004) Chondrocyte mechanotransduction: effects of compression on deformation of intracellular organelles and relevance to cellular biosynthesis. Osteoarthritis and Cartilage 12(12):937 - 946

Urban JPG, McMullin JF (1985) Swelling pressure of the intervertebral disk: influence of proteoglycan and collagen contents. Biorheology 22(2):145-157

Wang N, Butler J, Ingber D (1993) Mechanotransduction across the cell surface and through the cytoskeleton. Trends in Cell Biology 3(8):257 - 257 